\title{
O PROCESSO DE ADOECER DO PORTADOR DE COLOSTOMIA POR CÂNCER ${ }^{1}$
}

SôniaAyako Tao Maruyama²

Márcia Maria Fontão Zago ${ }^{3}$

Maruyama SAT, Zago MMF. O processo de adoecer do portador de colostomia por câncer. Rev Latino-am Enfermagem 2005 março-abril; 13(2):216-22.

Compreender como os portadores de colostomia por câncer e seus familiares percebem o processo do adoecer é o objetivo deste estudo. Os referenciais teóricos e metodológicos que fundamentaram o estudo foram a antropologia interpretativa, a antropologia médica e a etnografia. Os dados foram obtidos por meio de entrevistas, sob a forma de narrativas, e observações junto a doze portadores de colostomia e cinco familiares, no período de junho de 2002 a maio de 2003. Da análise dos dados identificamos a categoria: A vida antes da colostomia por câncer. Os dados permitiram compreender que a experiência de ter uma colostomia por câncer é uma construção sociocultural.

DESCRITORES: colostomia; neoplasias; antropologia cultural

\section{THE SICKENING PROCESS OF COLOSTOMY PATIENTS BY CANCER}

This study aimed to understand how patients with colostomy by cancer and their family members perceive the sickening process. The theoretical and methodological reference frameworks the study was based on were anthropology and ethnography. Data were collected through interviews, in a narrative form, and observations with twelve colostomy patients and five family members, in the period from June 2002 to May 2003. The analysis allowed us to understand that the experience of having a colostomy by cancer is a social-cultural construction.

DESCRIPTORS: colostomy; neoplasms; anthropology, cultural

\section{EL PROCESO DE LA ENFERMEDAD DEL PORTADOR DE COLOSTOMÍA POR CÁNCER}

La finalidad de este estudio fue comprender como los portadores de colostomía por cáncer y sus familiares perciben el proceso de la enfermedad. Los referenciales teóricos y metodológicos que fundamentaron el estudio fueron: la antropología interpretativa, la antropología médica y la etnografía. Los datos fueron obtenidos por medio de entrevistas, en forma de narrativas, y observaciones de doce pacientes de colostomía y cinco familiares, en el período de Junio del 2002 a Mayo del 2003. Del análisis de los datos identificamos la categoría: la vida antes de la colostomía por cáncer. Los datos permitieron comprender que la experiencia de tener una colostomía por cáncer es una construcción sociocultural.

DESCRIPTORES: colostomía, neoplasias; antropología cultural

\footnotetext{
${ }^{1}$ Trabalho extraído da tese de doutorado apresentada à Escola de Enfermagem de Ribeirão Preto, da Universidade de São Paulo, 2003; ${ }^{2}$ Enfermeira, Professor da Universidade Federal do Mato Grosso, e-mail: soniayako@uol.com.br; ${ }^{3}$ Enfermeira, Professor Livre-Docente da Escola de Enfermagem de Ribeirão Preto, da Universidade de São Paulo, Centro Colaborador da OMS para o desenvolvimento da pesquisa em enfermagem, e-mail: mmfzago@eerp.usp.br
} 


\section{INTRODUÇÃO}

O câncer pode afetar, entre outros órgãos, o intestino grosso. Dentre os cânceres do intestino, o colorretal refere-se a uma neoplasia que atinge o cólon e o reto ${ }^{(1)}$.

No Brasil, nas regiões Sul, Sudeste e Centro-Oeste, o câncer de cólon e reto é reconhecido como o quarto mais freqüente em homens e o terceiro mais freqüente em mulheres. 0 número de casos novos previstos para o ano de 2005 é da ordem de 12.410 casos em homens e de $13.640 \mathrm{em}$ mulheres. 0 risco estimado é de 14 casos novos para 100 mil homens e 15 para cada 100 mil mulheres ${ }^{(2)}$.

Os dados demonstram a relevância da doença, para ambos os sexos, não só pela morbidade e possibilidade de realização da colostomia, mas também pelas altas taxas de mortalidade ${ }^{(2)}$.

O tratamento do câncer colorretal consiste de procedimento cirúrgico, quimioterapia e radioterapia, sendo as duas últimas terapias associadas à cirurgia. A ressecção cirúrgica do local afetado e a realização de uma colostomia permanente constituem-se na mais efetiva terapia para o câncer colorretal ${ }^{(3)}$. A terapêutica cirúrgica consiste na ressecção do cólon e do reto, quando o cirurgião realiza, concomitantemente, a ostomia, que desvia o trajeto intestinal para uma abertura criada na parede abdomina ${ }^{(4)}$.

A ostomia é considerada uma das mais importantes realizações cirúrgicas porque possibilita a sobrevida da pessoa acometida por câncer colorretal. Apesar da aceitação desse procedimento por parte dos profissionais de saúde, parece que, para o portador de colostomia, torna-se um processo complexo.

Durante as nossas atividades profissionais desenvolvidas junto a pessoas com ostomias, percebemos que os portadores de colostomia por câncer e seus familiares apresentam variados comportamentos em relação à doença e ao tratamento. As experiências de vida antes da doença e o processo do adoecimento que influencia nos significados que as pessoas dão a si mesmas, à doença, ao tratamento e à própria existência da colostomia, conduziram-nos à cultura como a dimensão que orienta o comportamento das pessoas. Esses significados podem ser objetivados, alcançando-se a dimensão subjetiva e intersubjetiva dessas pessoas, e possibilitam compreender a relação entre condições de vida das pessoas e os significados atribuídos à saúde e à doença.

A culturaé uma trama de significados construída pelo próprio homem, e esses significados são compartilhados pelo grupo sociale servem de orientação para a conduta dos seus membros ${ }^{(5)}$.

O Modelo Explicativo (ME) permite diferenciar as construç̧ões culturais do processo de adoecer e dos sistemas de cura sociais, nos quais se fazem presentes três sistemas de cuidados à saúde: 0 sistema familiar, o sistema popular e o sistema profissional, sobrepostos entre si. 0 autor diferencia os termos de disease, illness e sickness ${ }^{(6)}$, que foram traduzidos para a língua portuguesa da seguinte forma: illness como enfermidade; disease refere a patologia e o sickness como doença. A enfermidade está associada à forma como a pessoa doente, os membros da família ou a sua rede social percebem, vivem e respondem aos sintomas orgânicos e à incapacidade física; à patologia, ao problema de saúde na perspectiva do profissional, nos termos biológicos; e à doença, à desordem, no sentido genérico, usado pela população, relacionado com as forças macrossociais ${ }^{(7)}$.

A experiência da enfermidade tem por base a experiência humana dos sintomas e do sofrimento pelo doente, família e sociedade. Por isso, os modelos explicativos só podem ser compreendidos pela análise do contexto específico em que são empregados ${ }^{(6)}$.

O contexto em que acontece a doença, as suas experiências da vida, as suas relações sociais, a sua bagagem de conhecimento, a sua orientação de vida, as suas crenças e seus valores pessoais, ou seja, o conhecimento do senso comum afeta o significado do adoecer.

A vivência de um câncer e de uma colostomia, a qual muda permanentemente a vida diária do sujeito, constitui um dos momentos mais críticos da vida de uma pessoa, por implicar um sistema complexo de análise e reflexão da própria biografia, cujos significados foram construídos ao longo das suas experiências de vida.

Assim, com o objetivo de compreender o processo do adoecer do portador de colostomia por câncer, sob a ótica dos portadores de colostomia e seus familiares, o referencial metodológico mais adequado a esse objetivo foi o da etnografia, pois focaliza a cultura e o processo de saúde e a doença. Compreender esse processo pode minimizar a lacuna entre o conhecimento do profissional e o conhecimento do senso comum, melhorando a assistência de enfermagem.

\section{MATERIAL E MÉTODO}

O estudo foi desenvolvido sob a abordagem metodológica da etnografia, pois possibilita compreender os significados, as intenções e o universo simbólico dos sujeitos, de modo a favorecer uma atuação consciente e respeitadora dos universos culturais dos diferentes segmentos e grupos de pessoas ${ }^{(8-10)}$.

Este estudo foi aprovado pelo Comitê de Ética e Pesquisa do Hospital Universitário Júlio Muller (HUJM).

As etapas seguidas no estudo foram: a escolha da situação social, o trabalho de campo e a análise dos dados.

A situação social foram os portadores de colostomia por câncer e seus familiares vinculados ao Ambulatório de Ostomias do HUJM, em Cuiabá-MT.

O trabalho de campo ocorreu de junho de 2002 a maio de 2003. Os critérios adotados para a seleção foram: ser portador de colostomia permanente por câncer, ter conhecimento do diagnóstico de 
câncer, estar na cidade no momento da entrevista, ser maior de idade, poder se comunicar verbalmente, sentir-se em boas condições clínicas e concordar em participar do estudo, tendo assinado o termo de consentimento livre e esclarecido.

As aproximações com o campo de estudo e com os sujeitos do estudo foram graduais. Iniciamos observando as pessoas que buscavam o serviço, as situações, o contexto e as reações. Em seguida, selecionamos os portadores de colostomia e os familiares. O registro no cadastro do Ambulatório foi outro recurso adotado para a seleção dessas pessoas.

Os familiares selecionados foram indicados pelos próprios portadores de colostomias. Não necessitavam ter vínculo consangüíneo com o portador, mas fazer parte da família.

Assim, o grupo de informantes foi constituído por doze portadores de colostomia por câncer e cinco familiares. Dos portadores de colostomia por câncer, 10 pessoas tinham como diagnóstico o câncer colorretal, e 2, o câncer em outros órgãos.

A coleta de dados ocorreu por meio de entrevistas e observação participante realizada no Ambulatório ou no domicílio dos sujeitos. A estratégia adotada para a realização da entrevista foi a forma narrativa, considerada a mais adequada para acessar as experiências das pessoas com colostomia por câncer e seus familiares, e compreender a influência do contexto no processo de adoecer. As questões orientadoras para os portadores de colostomia por câncer foram: "Conte-me sobre sua história de vida", "Fale como vê a doença, o câncer", "Conte-me como é ser portador de colostomia por câncer" e, para os familiares foram: "Qual a sua relação com o paciente", "Fale-me como é viver com essa pessoa". Cada entrevista teve duração de 30 minutos a duas horas. Durante as entrevistas, buscamos não deixar que o gravador inibisse a pessoa, posicionando-o fora do alcance visual dos entrevistados. Muitas vezes, não foi preciso perguntar sobre o adoecimento, já que as pessoas o incluíam naturalmente nas suas narrativas. Em cada narrativa, procurávamos registrar alguma observação que nos tenha marcado durante a entrevista.

Os dados coletados das entrevistas foram transcritos com a ajuda de um digitador, corrigidos pelas pesquisadoras, para, posteriormente, seguir-se a fase de análise dos dados. O programa Ethnograph v5.0. foi utilizado na fase de transcrição dos dados. A análise das transcrições dos dados foi realizada manualmente.

O processo de análise dos dados consistiu de redução dos dados, ou seja, a codificação se deu concomitante às entrevistas, segundo critérios espaciais, temporais, temáticos, gramaticais e sociais. Cada frase ou parágrafo recebeu um código, baseando-se em seu conteúdo, e, posteriormente, eles foram reunidos em categorias, tendo como foco os elementos referenciais da cultura. Os códigos foram construídos após a coleta dos dados. Nessa transformação, fomos definindo a interpretação e a compreensão das experiências dos sujeitos, segundo suas construções culturais. A construção dos códigos e da categoria foi avaliada por dois pesquisadores atuantes na abordagem dos métodos qualitativos.

Assim, das entrevistas e observações dos portadores de ostomias por câncer e seus familiares, emergiram códigos que foram reunidos em uma grande categoria: A vida antes da colostomia por câncer e o processo de adoecer. Dessa categoria surgiram 6 subcategorias: aspectos marcantes da vida antes da colostomia, a entrada da pessoa no reino da doença, a busca por ajuda para sua doença, o corpo como o locus do câncer, as explicações para o câncer, os estigmas para o câncer.

\section{RESULTADOS E DISCUSSÃO}

Das narrativas obtidas, apreendemos os diferentes aspectos orientados pelo processo de socialização dos portadores de colostomia por câncer e seus familiares, no qual a cultura compartilhada é tida como referência para as diversas experiências das pessoas que fazem parte do contexto de cuidado à saúde.

A vida antes da colostomia por câncer e o processo de adoecer

Essa categoria permitiu extrair seis subcategorias: aspectos marcantes da vida antes da colostomia, a entrada da pessoa no reino da doença, a busca por ajuda para sua doença, o corpo como o locus do câncer, as explicações para o câncer, as explicações para o câncer e os estigmas do câncer.

Aspectos marcantes da vida antes da colostomia

Os portadores de colostomia por câncer narraram fragmentos das suas histórias de vida destacando as lembranças de várias situações, nas diversas fases da vida: na infância, na adolescência e na vida adulta. Dessas fases, a infância teve destaque, por ser uma fase da vida considerada de alegrias, de liberdade, sem preconceitos, mas que foram interrompidos, devido às dificuldades relacionadas às condições sociais e familiares da época. Nesse retrocesso temporal, percebemos a importância atribuída ao trabalho, ao estudo e ao uso da vestimenta diária:

Eu morava num sítio e quem mora num sítio sempre trabalha muito na roça. Estudei muito pouco porque tinha vez que era safra de farinha e tinha que ficar em casa fazendo a farinha, a semana inteira... Não estudei nada, não aproveitei nada! Sinto não ter tido oportunidade de estudar! (Bruna).

As diversas fases da vida anteriores ao adoecimento serviram para a assimilação e à incorporação dos valores, dos sentimentos e das crenças do grupo social, no qual a família se constituiu um elemento 
importante na construção de cada pessoa e na formação dos sentimentos ambíguos, tais como: alegria-tristeza, liberdade-arrependimento, brincadeira-trabalho.

A vida anterior ao adoecimento é repleta de sentimentos e situações contraditórias que marcam o ser humano e que dão significados para cada momento vivido, porém a vida saudável é a base das relações e das experiências; a doença nunca é considerada como uma possibilidade. A vida saudável supera os momentos de tristeza e perdas, embora as dificuldades sejam vivenciadas como parte do cotidiano social e cultural dessas pessoas.

As pessoas dão significados aos acontecimentos pelas formas como estes são percebidos pelos familiares e por sua rede de relações. Cada pessoa é construída tendo por referência o outro, que compartilha e influencia os significados dos contextos socioculturais vinculados a uma estrutura socioeconômica, que integra a sociedade como um todo. A influência do contexto na formação das pessoas permite dizer que ela tem uma "dimensão fabricada culturalmente"(11).

A entrada da pessoa no reino da doença

A vida comum dos portadores de colostomia por câncer e de seus familiares foi interrompida com as mudanças percebidas no corpo. Nessa fase, a doença foi percebida de forma diversa por cada informante, pois cada pessoa interpreta as mudanças no corpo segundo seus conhecimentos e experiências de vida.

Para os portadores, a descoberta da doença deu-se com o sangramento anal e as disfunções intestinais. Foi comum, entre as pessoas, a associação entre evacuação, sangramento, ressecamento e a ocorrência de hemorróida:

... trabalhando, descobri(...) eu achava que era hemorróida, fui automedicando, tomando castanha da índia (..). Vique não estava melhorando, estava piorando, o cocô vinha sujo de rajas de sangue. Estranhei, mas pensei que era hemorróida (Vitória).

Essa interpretação é influenciada pela cultura. A cultura ajuda a dar forma às mudanças físicas e emocionais difusas, colocando-as dentro de um padrão identificável para a pessoa "doente" e para as pessoas que a cercam. As desordens físicas iniciais foram incluídas pelas pessoas no âmbito de uma "doença normal" e tratadas com base no seu conhecimento e na sua rede de relações.

Há uma tendência, para pessoas de um mesmo grupo social, em considerar certas evidências como naturais ${ }^{(6)}$. A cultura possibilita a construção de um padrão de sinais e sintomas, caracterizando-os como uma doença popular $^{(12)}$. As manifestações e suas interpretações pelos portadores de colostomia conduziram-nos a negligenciar a importância dessas como um sinal do câncer colorretal. A negligência pode estar associada ao desconhecimento das pessoas sobre os sinais básicos dessa doença. Conhecer o significado das manifestações na população subsidia os profissionais de saúde a atuarem em programas de prevenção e detecção precoce desse tipo de câncer.

A desordem orgânica dos portadores de colostomia por câncer foi associada ao contexto da vida de cada um. A ruptura da normalidade do corpo conduz as pessoas a fazer reflexões existenciais, em busca de explicações que se enquadrem nos limites de suas crenças, valores e comportamentos, enfim, no conhecimento adquirido das experiências de vida de cada um, chamado de background cultural do indivíduo. Esse conhecimento, por sua vez, exerce forte influência nas percepções e emoções em relação à doença ${ }^{(12)}$. A interpretação atribuída ao evento depende da experiência pessoal e do significado que a pessoa lhe confere e constitui um meio para organizá-las ou reorganizá-las de maneira a dar um sentido ao evento em sua vida.

A busca por ajuda para sua doença

A interpretação das mudanças corporais como um problema de saúde comum, uma desordem passageira, "natural" e que pode ser facilmente "curada", levou-os a buscar por ajuda no seu sistema de cuidado familiar e popular.

O uso do tratamento popular foi uma decisão tomada pelos portadores de colostomia, como nos retrata a expressão: eu achava que era hemorróida, fui automedicando, tomando castanha da índia (Vitória).

A busca pelo cuidado de saúde no sistema familiar, na sua rede de relações, e o prestígio por cuidados de saúde popular têm uma explicação histórica, pois, só nos últimos dois séculos, com 0 processo de urbanização, é que a hegemonia do cuidado à saúde popular passou para o sistema de cuidado profissional. Mesmo existindo benzedoras(es) e curandeiras(os) nas cidades, as condições de vida urbana dificultaram a permanência desse saber tradicional, por limitar 0 acesso ao meio natural e desorganizar a rede de relações sociais que sustentam as relações terapêuticas e as regras de transmissão de conhecimentos de um curandeira(0) para outra(0) ${ }^{(13)}$. Esse breve relato histórico explica a forte tendência dos brasileiros em utilizar os saberes e as práticas populares como a primeira medida para cuidar do corpo doente.

O corpo como o locus do câncer

As medidas utilizadas pelos portadores, com base no sistema de cuidado informal, às manifestações corporais não foram suficientes para ordenar suas alterações físicas, que persistiam. Os portadores de colostomia passaram a interpretar as mudanças físicas apresentadas como uma condição anormal, como na expressão: ....aí percebi que a saúde não estava mais boa, estava com essa doença (Gustavo).

O seu corpo foi a referência para a interpretação das manifestações corporais. O corpo, a matéria de vinculação das pessoas 
ao mundo, antes de ser um objeto de intervenção das ciências biomédicas, é a dimensão do nosso próprio ser. O corpo é o local da experiência e da prática da vida e, portanto, a reflexão sobre este é posterior à sua experiência. Nesse enfoque, o modo como as pessoas vivenciam uma doença é, primeiro, uma síntese entre corpo e cultura, para, depois, ser uma reflexão sobre a doença ${ }^{(14)}$.

À medida em que as pessoas vivem as mudanças, segue-se um processo reflexivo, segundo o conhecimento de cada um e 0 significado social e psicológico do corpo. A percepção do corpo e suas interpretações são informadas pela cultura da qual a pessoa participa. A função social do corpo, associada ao exercício do trabalho, orientou a percepção da mudança corporal como uma doença: ...ele nem agüentava mais trabalhar (esposa de Gustavo).

Nas sociedades ocidentais, o corpo é desvinculado do ser humano. Esse isolamento, contribuiu na formação de um vocabulário anatômico e fisiológico, utilizado pelo sistema de saúde, que só faz sentido dentro da sua esfera ${ }^{(15)}$ e na ruptura ontológica entre o cosmo e o corpo humano e a dissociação do ser humano do seu corpo. Criase, assim, uma ambigüidade em torno da noção de ser humano: o fato de ser e de ter um corpo. Os portadores, ao valorizarem as mudanças corporais, demonstram essa ruptura entre ter e ser, como aparece na narrativa: ... eu estava ressecada, minha obra era quente. Eu ia ao banheiro fazer necessidades e só saía sangue ... (Larissa).

O corpo, então, constitui-se no espaço de origem da doença, ela tem uma forma, causas e sintomas ${ }^{(16)}$.

O processo de significar a saúde e a doença entre os portadores e seus familiares consiste em um complexo mecanismo da percepção dos significados culturais, influenciado por construções históricas a respeito do corpo.

$\mathrm{O}$ adoecimento para os portadores e seus familiares rompe com os pressupostos da vida cotidiana, questiona o conhecimento adquirido na vida e gera dúvidas e incertezas ${ }^{(14)}$. Na tentativa de reorganizar a desordem do corpo, essas pessoas partem em busca do conhecimento profissional. A figura do médico constitui o símbolo que delimita essa passagem, revelada pela expressão eu fui atrás do médico para fazer consulta (esposa de Gustavo). É ele que representa, no cuidado profissional, a pessoa que irá proporcionar a cura da desordem.

Nessa passagem, a desordem que tinha relação com a biografia de cada um, no sistema de cuidado à saúde profissional, constitui-se uma entidade orgânica e é enquadrada numa extensa classificação, para a qual se dá um nome, um tempo e determina-se a cura.

A desordem é chamada de câncer, como diz a expressão a médica foi soltando na minha cara que era câncer, que eu estava com câncer (Bruna). O conhecimento médico limita-se a questões técnicas do problema de doença, e o significado dos sintomas não vai além da semiótica do diagnóstico ${ }^{(6)}$. No sistema profissional, as palavras e as expressões indicam que as alterações são ao nível do sistema gastrointestinal: o cocô com gosma, quando evacuava doía, ficava sangrando, parecia que tinha um caroço, as fezes já tava vindo com muita dificuldade, o intestino parou, obra quente e recebem nomenclaturas específicas, como: obstipação, obstrução intestinal e tumoração. A "biópsia" certifica 0 câncer, e a pessoa tem o seu status alterado, passando a ser o paciente. Confirma-se a doença e o doente, ambos do âmbito de atuação do sistema de saúde profissional.

A entrada do portador de colostomia no sistema profissional é marcada pela "despersonalização" (12), por negligenciar o sujeito e sua história, seu meio social, sua relação com o desejo, a angústia, a morte e o sentido da doença ${ }^{(15)}$.

As explicações para o câncer

Ter 0 câncer e a colostomia constituem situações que ameaçam a vida, o que conduz essas pessoas a reinterpretar eventos passados para explicar o que causou sua doença, unindo elementos do conhecimento popular e da biomedicina ${ }^{(6)}$. Nessa busca, encontram associações com os contextos vivenciados antes do adoecimento, indicando que a sua doença tem relação com cada biografia.

... a minha filha que saiu de perto de mim. Ela separou do marido... Minha tia levou ela para São Paulo. Na época que ela foi, fiquei doente e internei. Nessa época, foi muito difícil! Ela longe! Senti muito dela não estar aqui... (Bruna).

Se, para algumas pessoas, o câncer é relacionado a uma causa externa, para outros, a doença é associada a uma causa interna, como o hábito de vida. Essa noção tem contribuído para o sentimento de culpa que, muitas vezes, acompanha a doença. Adoença dela foi um pouco de descuido (esposo de Giovana).

Ainda, a doença foi atribuída a uma dimensão sobrenatural. Deus quis assim, vamos aceitar. Deus não quer que a gente fica doente mas aconteceu (Larissa).

No contexto das diversas explicações para o adoecimento dos portadores e seus familiares sobre a doença, percebemos que ela não está centrada no corpo físico, mas é fruto da relação de outras dimensões que integram a vida dessas pessoas, ou seja, a dimensão pessoal, social e sobrenatural ${ }^{(12)}$.

Buscar a origem do câncer colorretal é buscar o sentido para o que lhe aconteceu, é buscar uma base para as ações realizadas, para lidar com a realidade e justificar seus comportamentos. Ao narrarem as origens da doença, os sujeitos não o fizeram prontamente; muitos demonstraram incertezas, demonstrando que não era algo simples. Aos poucos, as crenças foram sendo relacionadas à condição de cada um. 
Os estigmas do câncer

A interpretação e a reação à doença pelas pessoas são influenciadas pelos estigmas sobre o câncer e pelo modo como cada pessoa, segundo seu conhecimento particular, entende esses estigmas. O termo estigma é utilizado para fazer referência a algo que marca, que discrimina, como o câncer e a colostomia.

A noção de que o câncer é um ente, tem forma e tamanho e necessita ser extraído por meio de uma intervenção cirúrgica, para remover não só o câncer mas também a parte do corpo afetada, leva à correspondência entre câncer e mutilação. Em nossa sociedade, a mutilação do corpo é um símbolo de estigma, como aparece no trecho: (perguntei se preferia morrer a ficar com a colostomia) É claro. Se não morrer hoje, morre amanhã. Para que a gente ficar sofrendo! (José).

A incurabilidade do câncer emergiu nos relatos: Quanto mais se mexe, mais pior fica (Gabriel), Eu acho que eu não tinha câncer porque quem tem câncer não sara (Pedro).

O estigma de doença grave é motivo de sujeição aos preconceitos e de encobrir a situação e está presente nos comportamentos das pessoas. As maneiras de falar sobre o diagnóstico, os rituais utilizados para dar ou não a notícia, o contexto pacienteprofissional em que se dá a informação sobre o diagnóstico são aspectos percebidos como influentes nas reações à doença e ao tratamento. As reações à doença parecem estar intimamente relacionadas ao comportamento que os profissionais têm em relação à doença.

As noções da doença e do tratamento, originadas no contexto sociocultural dos sujeitos, mostram que a doença tem múltiplas interpretações. As pessoas acometidas pela doença não a explicam por uma causa específica e única. As reações e os sentimentos dos portadores e seus familiares são fortemente influenciados pelos aspectos valorizados em nossa cultura como saúde, corpo perfeito e vida. Esses parâmetros são as referências pelos sentimentos de tristeza, depressão, sofrimento, medos e incertezas e, principalmente, pela impotência frente à declaração da finitude da vida, que acompanha essas pessoas. $A$ experiência de estar com câncer e ter uma colostomia causa impacto e sofrimento em função dos valores e crenças presentes na sociedade. Viver a experiência de portador de colostomia por câncer é confrontar os valores e as crenças do grupo com os valores e crenças pessoais.

\section{CONSIDERAÇÕES FINAIS}

Os dados obtidos no presente estudo permitiram compreender que os aspectos marcantes da vida antes da colostomia foram lembrados pelos portadores, pois, de alguma maneira, conectavam com a experiência do adoecimento. Os eventos passados contribuíram na formação dos valores, dos sentimentos, sendo que a família constituiu o elemento importante na construção da referência dessas pessoas. Para essas pessoas, sua vida antes do câncer foi normal. As mudanças no padrão intestinal foram interpretadas como sendo hemorróida, o que, em nossa cultura, não significa uma doença grave, mas uma desordem passageira e um fato natural. Esse significado levou-as a procurar cuidados no sistema de cuidado familiar e popular. Inicialmente, não houve mudanças nas suas atividades quotidianas, mas, com o passar do tempo, as pessoas começaram a perceber que tais mudanças estavam afetando a manutenção das suas rotinas. Essas percepções conduziram essas pessoas a buscar pelo sistema de cuidado à saúde profissional. Nesse sistema, a desordem adquire um nome e tem tratamento: o câncer e a colostomia e constituíram motivos de impacto, pois constituem condições estigmatizantes e de sofrimento. As explicações para a situação foram associadas ao seu contexto e à sua biografia. Finalizando, as narrativas da vida, antes do adoecimento, associadas ao processo de adoecer, mostram-nos que as experiências do adoecimento são construções de significados das diversas experiências pelas quais passam os portadores de colostomia, cujas referências são: o seu contexto, a sua família, as suas atividades. Por isso, muitos portadores reagem distintamente à situação: conformandose ou negando-se. Essa vivência constitui uma experiência corporal, reflexiva, vivida entre o corpo, entre si mesmo e a sociedade, mediada pela cultura ${ }^{(6)}$, um evento moldado culturalmente e, por isso, com múltiplos sentidos.

\section{LIMITAÇÕES DO ESTUDO}

Dentre as limitações deste estudo, relacionamos dois aspectos: o pequeno número de observação participante e a não unanimidade do diagnóstico de câncer colorretal, pois o critério adotado foi o de ter colostomia por câncer. Apesar dessas limitações, acreditamos que a sua realização foi importante, pois seus resultados podem provocar mudanças no contexto social.

\section{RECOMENDAÇÕES}

O profissional de saúde, especificamente o enfermeiro, ao conhecer o significado das percepções dos portadores de colostomia, pode melhorar a relação profissional-doente e contribuir para uma assistência que integre os aspectos culturais vividos pelas pessoas diante da sua alteração física. 


\section{REFERÊNCIAS BIBLIGRÁFICAS}

1. Winawer SJ, Cohen AM. Overview of adenocarcinoma of the colon and rectum. In: Cohen AM, Winawer SJ, Friedmas MA, Gunderson LL. Cancer of the colon, rectum, and anus. New York (USA): McGraw-Hill; 1995. p.7-10.

2. Ministério da Saúde (BR). Secretaria de Atenção à Saúde. Instituto Nacional de Câncer. Coordenação de Prevenção e Vigilância. Estimativa 2005: Incidência de Câncer no Brasil. Rio de Janeiro: INCA; 2004. 94p.

3. Hermaneck P, Sobin LH. Colorectal Carcinoma. In: Hermaneck P, Gospodarowiccz MK, Henson DE, Hutter RVP, Sobin, LH. Prognostic factors in cancer. New York (USA): Springer; 1995. p. 64-79.

4. Ortiz H, Marti Rague J, Foulkes B. Indicaciones y cuidados de los estomas. $2^{\text {a }}$ ed. Barcelona (ES): Editorial Jims; 1994.

5. Geertz C. A interpretação da cultura. Rio de Janeiro (RJ): LTC Livros Técnicos e Científicos; 1989.

6. Kleinman A. The illness narratives: suffering, healing and the human conditions. New York (USA): Basic Books; 1988.

7. Almeida N Filho. For a general Theory of Health: preliminary epistemological and anthropologial note. Cad Saúde Pública 2001 julago; 17(4):753-99.

8. Boyle JS. Styles of ethnography. In: Morse JM. Critical Issues in Qualitative research methods. California (USA): Sage Publications; 1994. p. 158-85.

9. Maggs-Rapprt F. "Best research practice"; in pursuit if methodological rigour. Adv Nurs 2001; 35(3):373-83.

10. Costa MCS. Intersubjetividade e historicidade: contribuições da moderna hermenêutica à pesquisa etnográfica. Rev Latino-am Enfermagem 2002 maio-junho; 10(3):372-82.

11. Velho G. Individualismo e cultura: notas para uma antropologia da sociedade contemporânea. Rio de Janeiro (RJ): Zahar Editores; 1981. 12. Helman CG. Cultura, saúde e doença. $2^{\mathrm{a}}$ ed. Porto alegre (RS): Artes Médicas; 1994.

13. Montero P. Da doença à desordem: a magia na umbanda. Rio de Janeiro (RJ): Edições Graal; 1985.

14. Alves PC, Rabelo M.C. Repensando os estudos sobre representações e práticas em saúde/doença. In: Alves PC, Rabelo MC, organizadores. Antropologia da saúde: traçando identidade e explorando fronteiras. Rio de Janeiro (RJ): Fiocruz; 1998. p.107-21. 15. Le Breton D. Anthropologie du corps et modernité. Paris (FR): PVF; 1998.

16. Foucault M. O nascimento da clínica. Rio de Janeiro (RJ): ForenseUniversitária; 1977. 